\title{
On the Recycling of a Biodegradable Polymer: Multiple Extrusion of Poly (Lactic Acid)
}

\author{
Livia Maria Garcia Gonçalves ${ }^{*}$ * (1); Talita Rocha Rigolina ; Bianca Maia Frenhe ${ }^{a}$; \\ Sílvia Helena Prado Bettini ${ }^{a}$ \\ ${ }^{a}$ Universidade Federal de São Carlos, Departamento de Engenharia Material, Rod. Washington Luiz, \\ Km 235, 13565-905, São Carlos, SP, Brasil.
}

Received: June 23, 2020; Revised: September 09, 2020; Accepted: September 19, 2020

\begin{abstract}
Poly (lactic acid) (PLA) was submitted up to five cycles of extrusion in order to evaluate the effect of mechanical recycling. The material was evaluated under two conditions, thoroughly dried before processing and without drying. The changes in the molecular weight, acidity, thermal properties and coloring were assessed after each extrusion, and with this information, mechanisms of degradation were purposed. Molecular weight was reduced at a maximum of $30 \%$ after the most aggressive condition; five cycles without drying, which caused also an increase in acidity due to hydrolysis. Thermal properties were not significantly altered, which in combination to the molecular weight decrease allow to infer the recyclability of PLA. However, the most degraded samples had developed strong yellowing, particularly for samples without drying, which could be a problem for final products.
\end{abstract}

Keywords: Poly (lactic acid), Poly lactide, Degradation, Recycling, Multiple Extrusion.

\section{Introduction}

As environmental issues are gaining importance over the years, the use of fossil materials and the polymeric waste production are targets of several efforts and studies to their reducing. Poly (lactic acid) (PLA), or polylactide, is a material of interest in this context, for being biodegradable and originated from renewable sources ${ }^{1,2}$.

PLA is one of the more outstanding polymer among biodegradable and green polymers, for being commercially available in large-scale production and wide range of grades, which enables all usual thermoplastic processes of manufacture such as extrusion, injection molding, blow molding, blown film extrusion, and with these, several possibilities on packaging applications. Due to its biocompatibility, it has also several biomedical applications like sutures, scaffolds and drug carriers. PLA nowadays represents about $10 \%$ of the bioplastics market ${ }^{3-5}$.

PLA properties, such as good processability, mechanical properties, thermal stability and low environmental impact, which make it a substitute to commodities in well-established sectors. For instance, the Life Cycle Assessment (LCA) of PLA drinking bottles in comparison to PET bottles, shows a gain on reducing global warming potential, reducing dependency on fossil energy and decreasing human toxicity. Also considering that not always the End of Life of the product is taken on LCA account, the recyclability as a manner of extend its service life, before disposal on proper facilities to biodegrade, could make PLA an even better alternative ${ }^{6-8}$.

Mechanical reprocessing is one of the simplest routes to extend the service life of a polymeric material and environmentally superior to chemical recycling, however it has also some complexities, particularly when applied to waste

*liviagarciagoncalves@gmail.com materials, which require additional processes of separating and washing. Even though in the mechanical reprocessing of non-waste materials, there is always associated degradation mechanisms due to the presence of heat, shear stresses, and in the case of polycondensates as PLA, moisture ${ }^{3,5,9}$. The degradation mechanisms of PLA are very complex and involve hydrolysis, non-radicalar reactions such as transesterifications, cis-eliminations and radicalar reactions as well ${ }^{10}$. Understanding the mechanisms of degradation during processing may be a good starting point to consider the use of additives or variation of processing variables to reduce degradation and allow more cycles of processing.

Several studies have been conducted on the topic of mechanical recycling of PLA. Beltran and co-authors ${ }^{11}$ have found that the thermal stability and crystallinity of PLA have not changed after reprocessing, as well as clarity and barrier properties, suggesting that the recycled PLA could be reused for applications such as packaging. However, the studies of Zhao and co-authors ${ }^{12}$ on the recycling of 3D-printing PLA show that the polymer could not be reprocessed up to two cycles without severe loss of properties and viscosity. This could be an indication of the role of additives on degradation present on different grades of PLA for different applications. Another strategy for reprocessing PLA is using chain extenders to overcome the possible molecular weight reduction during recycling. The introduction of the chain extenders, in general, results to an improvement of properties such as molecular weight, MFI, thermal and mechanical properties $^{13,14}$. Although, this could be an unnecessary step when the reprocessing causes little change on the properties of interest as discussed above.

This study aimed to assess the effects of multiple extrusions on PLA with different levels of moisture, with focus on the 
molecular weight changes, acidity and discoloration, as well as the possible correlations of those effects with the reaction mechanisms of degradation.

\section{Experimental}

\subsection{Materials}

PLA used in multiple extrusions was Ingeo ${ }^{\mathrm{TM}}$ Biopolymer $7001 \mathrm{D}$ (NatureWorks LLC) with MFR of $6 \mathrm{~g} / 10 \mathrm{~min}$ $\left(210^{\circ} \mathrm{C}, 2.16 \mathrm{~kg}\right)$.

\section{2 Multiple extrusion of PLA}

Multiple extrusions were conducted in a co-rotating twin-screw extruder, B\&P Process Equipment and Systems, model MP19, with screw diameter of $19 \mathrm{~mm}$ and length/ diameter (L/D) ratio of 25 . Temperature profile was set at 150 , $180,180,180,180$ and $180^{\circ} \mathrm{C}$ and screw speed of $100 \mathrm{rpm}$. PLA was extruded under different reprocessing conditions: using a dried PLA prior to each cycle of extrusion and without drying. In latter case, PLA was used before the first extrusion as is, stored at room temperature, with no humidity control, and thereafter it was extruded sequentially with cooling in a bath of water and without drying between the steps. For the first condition (reprocessing of dried PLA), samples were dried for at least $4 \mathrm{~h}$ in a vacuum oven at $75^{\circ} \mathrm{C}$.

\subsection{Characterization}

Samples were characterized by titration of the acid groups, molecular weight measurements, thermal properties and yellowness index.

Acidity percentage was acquired by titration of the acid groups with $0.04 \mathrm{M}$ ethanolic $\mathrm{KOH}$ solution, using phenolphthalein as indicator, and a back titration was achieved with $0.04 \mathrm{M} \mathrm{HCl}$ solution in isopropyl alcohol. Samples were dried and solubilized in chloroform $(0.5 \mathrm{~g}$ of sample in $50 \mathrm{~mL}$ solvent), at room temperature, until complete solubilization. Acidity percentage in the samples was calculated through Equation 1:

$\%$ acidity $=\left(\frac{V_{e} * C_{K O H} * M_{c a}}{m}\right) * 100$

Where, $\mathrm{V}_{\mathrm{e}}$ is the equivalent volume of $\mathrm{KOH}$ added $\left(\mathrm{V}_{\mathrm{KOH}}+\mathrm{V}_{\text {excess }}{ }^{\mathrm{e}}-\mathrm{V}_{\mathrm{HCl}}\right), \mathrm{C}_{\mathrm{KOH}}$ molar concentration of $\mathrm{KOH}, \mathrm{M}_{\text {ca }}$ is the molar mass of PLA carboxylic acid group (45 g/mol) and $\mathrm{m}$ is the mass of the sample. All titrations were performed in triplicate. This methodology is better described in ${ }^{15}$.

Relative molecular weights of samples were determined using Malvern Viscotek_HT-GPC liquid chromatograph equipped with refractive index detector and operating with tetrahydrofuran (THF) as solvent and test temperature of $50^{\circ} \mathrm{C}$. Main flow (column) and auxiliary flow (detector) of $1.0 \mathrm{~mL} / \mathrm{min}$ were employed. A calibration curve was obtained from polystyrene (PS) standards.

Thermal analyses were carried out in a differential scanning calorimeter, TA Universal Analysis, model Q100. Samples were submitted to two heating cycles at a rate of $10^{\circ} \mathrm{C} / \mathrm{min}$, from $20^{\circ} \mathrm{C}$ to $200^{\circ} \mathrm{C}$, under a nitrogen atmosphere and $5 \mathrm{~min}$ isothermal at $200^{\circ} \mathrm{C}$ (after first heating) and at $20^{\circ} \mathrm{C}$ (after cooling). Thermal properties were determined from the second heating cycle.

Yellowness index were measured with a BYK spectro-guide sphere gloss colorimeter obtaining the CIELab coordinates of color from three different points of square samples, with same thickness of $1.1 \mathrm{~mm}$, obtained by melt pressing in a mold. Averages of the CIELab coordinates were calculated for the virgin material, and material retrieved from first, third and fifth cycles of extrusion. The yellowness index for each sample was calculated according to ASTM E313.

\section{Results}

Table 1 shows the molecular weight number- and weightaverage (Mn and Mw, respectively) and the polydispersity index (PDI, Mn/Mw) calculated from the SEC curves. The proper drying protocol of the virgin material reflects on its very little degradation, with a reduction of approximately $2 \%$ of molecular weight averages on the first extrusion. However, drying alone could not avoid subsequent degradation due to the influences of heat and shear stresses of the extrusion process, the decrease on molecular weight is around $5 \%$ per cycle (Table 1 - Dried PLA).

According to Yu et $a l^{6}$, with the thermal degradation of PLA, the random mechanisms would cause an increase of the polydispersity value towards 2 , the theoretical value of PDI for condensation polymers. In their work, this evolution of the PDI values to 2 , is followed with a severe decrease, of at least half, of the original molecular weight.

Considering that the reduction of molecular weight for the present results is, at maximum, of $20 \%$ for this set of dried samples, a steep increase of polydispersity is not expected, yet

Table 1: Molecular weight averages after multiple extrusions obtained by SEC

\begin{tabular}{|c|c|c|c|c|c|c|}
\hline \multicolumn{7}{|c|}{ Dried PLA } \\
\hline & Virgin & $1^{\text {st }}$ cycle & $2^{\text {nd }}$ cycle & $3^{\text {rd }}$ cycle & $4^{\text {th }}$ cycle & $5^{\text {th }}$ cycle \\
\hline$M_{n}$ & 126800 & 124300 & 119500 & 112000 & 103500 & 99100 \\
\hline$M_{w}$ & 223400 & 219800 & 210600 & 203200 & 190700 & 184000 \\
\hline IPD & 1.762 & 1.769 & 1.762 & 1.815 & 1.842 & 1.857 \\
\hline \multicolumn{7}{|c|}{ Humid PLA } \\
\hline & Virgin & $1^{\text {st }}$ cycle & $2^{\text {nd }}$ cycle & $3^{\text {rd }}$ cycle & $4^{\text {th }}$ cycle & $5^{\text {th }}$ cycle \\
\hline$M_{n}$ & 123400 & 122500 & 110600 & 100200 & 90600 & 84000 \\
\hline$M_{w}$ & 229600 & 223600 & 206700 & 189800 & 174700 & 161700 \\
\hline IPD & 1.861 & 1.825 & 1.869 & 1.895 & 1.928 & 1.925 \\
\hline
\end{tabular}


values rise from 1.76 to 1.86 with the extrusions. Therefore, random mechanisms of degradation are predicted.

Most of the mechanisms proposed in the literature for the thermal degradation of PLA such as, transesterification, cis-elimination, and the radicalar mechanisms, which are plausible to occur during extrusion, due to the presence of shear stresses, are characterized to be random ${ }^{17-19}$. Thus, polydispersity cannot define the main mechanism of degradation.

The averages in Table 1 (humid PLA) point to a very similar path when compared to the dried sample. However, the addition of moisture to this system causes an increase to the degradation conditions. First extrusion leads to a reduction of more than $2 \%$ of $\mathrm{Mw}$. The next cycles induce from 8 up to $9 \%$ of molecular weight decrease for each extrusion.

From the literature, a PLLA at room temperature with $65 \%$ of relative humidity has $0,3 \%$ in weight of moisture content $^{20}$. The material in this study has been stored in similar conditions. In the same way, on previous studies by our research group of the material in this present work, its immersion in water at room temperature resulted on a moisture content of $0,4 \%$ in weight, measured by Karl Fischer titration. Therefore, it is believed that the PLA uses has moisture percentage between 0,3 and $0,4 \%$. Thus, this may be the responsible for the increase on degradation caused by the first extrusion.

During extrusions, it was considered that the final extrudate material maintained a relatively constant amount of moisture, due to the balance of the evaporation of some moisture during the extrusion process at $180^{\circ} \mathrm{C}$ and the absorption of water

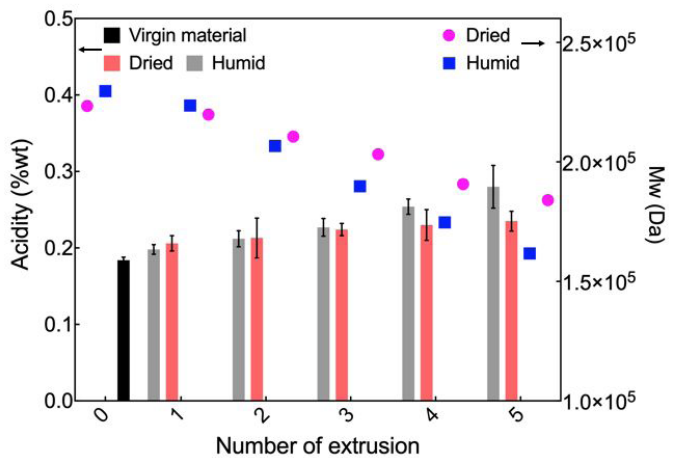

Figure 1. Acidity percentage and Mw for multiple extrusion samples on the cooling bath. The constant degradation percentage of each cycle corroborates to this hypothesis of a little and negligible moisture addition.

The higher degree of degradation caused by the presence of moisture indicates hydrolysis occur concurrently with thermal degradation. The mechanisms of hydrolysis, though, depends on the $\mathrm{pH}$ media. Assuming the initial content of moisture, and the presence of residual monomer, it is possible to consider a slightly acidic media to degradation. In this case, hydrolysis may happen with the protonation of a random carbonyl in the chain, or the protonation of the terminal hydroxyl group. The first route leads to a split in two chains of smaller molecular weight, while the latter results on the liberation of a lactic acid molecule and the reduction of one in the degree of polymerization of the former chain ${ }^{21,22}$.

With either mechanism, hydrolysis or thermal, degradation of PLA leads to an increase of chain ends, and part of these chain ends are carboxylic, which would cause an increase in the acidity of the samples. Figure 1 shows the weight percentage of acidity determined via titration of samples in a chloroform solution.

The acidity percentage increases with processing, very slightly, however, for the first three cycles, regardless of drying or not, but remaining relatively constant for the dried samples and noticeably higher for the last two cycles of the humid samples. The acidity increase for the latter is compatible with the reduction of molecular weight. This data also allows to infer about the degradation mechanism of hydrolysis, this increase would be possible when there is the formation of new chain ends (Figure 2a). If hydrolysis occurred by the second mechanism, with liberation of lactic acid as depicted on Figure 2b, these lactic acid molecules would be evaporated during processing or on drying prior to titration.

As for the thermal degradation, the mechanisms of reaction, either transesterification or cis-elimination (Figures 3a and 3b) are compatible with a decrease on molecular weight without a major increase on acidity, because some of the new structures formed with chain scission will be a cycle, and therefore not having a carboxylic end.). Radicalar degradations (Figure 4) would cause similar effects on acidity.

Thermal properties are shown on Table 2. From the table follows that the decrease of molecular weight does not alter significantly the thermal properties of the extrudates. There is a)<smiles>COC(=O)C(C)OC(=O)C(C)OC(=O)C(C)OC</smiles><smiles>COC(=O)C(C)OC(=O)C(C)O</smiles>

b)<smiles>COC(=O)C(C)OC(=O)C(C)OC(=O)C(C)O</smiles><smiles>COC(=O)C(C)OC(=O)C(C)O</smiles> 
a)

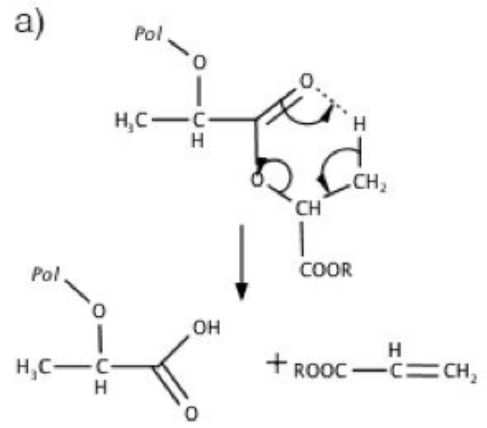

b)

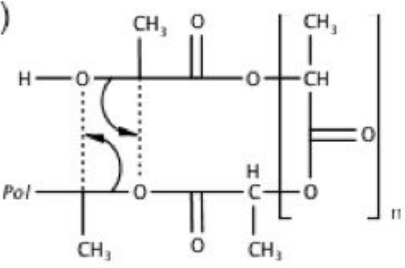

Pol $-\left.\right|_{\mathrm{CH}_{3}} ^{\mathrm{H}}+\mathrm{O}$<smiles>CC1OC(=O)C(C)OC(=O)C(C)OC1=O</smiles>

Figure 3. Schematic representations of chain scission reactions of PLA: a) cis-elimination; b) intramolecular transesterification. Adapted from ${ }^{18}$

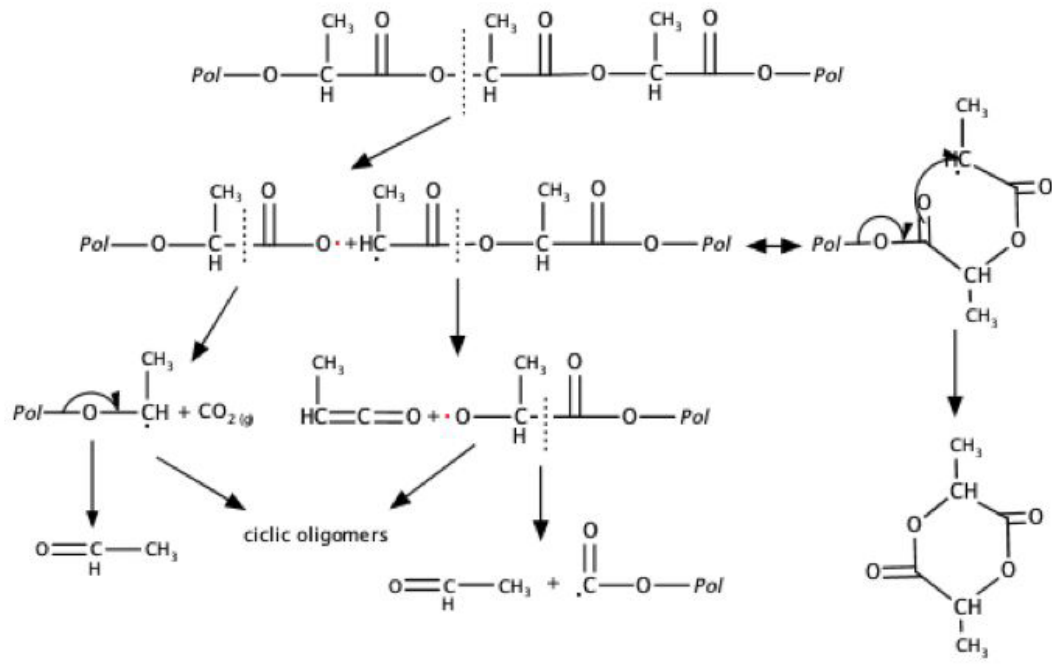

Figure 4. Example of a radicalar mechanism of PLA degradation. Adapted from ${ }^{23}$

Table 2: Thermal properties obtained by DSC for the multiple extrusion samples

\begin{tabular}{|c|c|c|c|c|c|c|}
\hline \multicolumn{7}{|c|}{ Dried PLA } \\
\hline & Virgin & $1^{\text {st }}$ cycle & $2^{\text {nd }}$ cycle & $3^{\text {rd }}$ cycle & $4^{\text {th }}$ cycle & $5^{\text {th }}$ cycle \\
\hline $\mathbf{T}_{\mathrm{g}}\left({ }^{\circ} \mathrm{C}\right)$ & 60.55 & 60.39 & 60.35 & 60.97 & 60.00 & 60.84 \\
\hline$T_{c}\left({ }^{\circ} \mathrm{C}\right)$ & 129.45 & 119.49 & 115.92 & 115.02 & 113.79 & 114.07 \\
\hline$\Delta \mathbf{H}_{\mathrm{cc}}(\mathrm{J} / \mathrm{g})$ & 0.977 & 20.59 & 22.47 & 23.50 & 26.20 & 23.69 \\
\hline $\mathbf{T}_{\mathrm{m}}\left({ }^{\circ} \mathrm{C}\right)$ & 151.28 & 151.16 & 150.27 & 150.95 & 149.40 & 150.19 \\
\hline$\Delta \mathbf{H}_{\mathrm{m}}(\mathrm{J} / \mathrm{g})$ & 1.161 & 23.80 & 23.75 & 22.26 & 26.29 & 26.65 \\
\hline$X_{c}(\%)$ & 1.2 & 25.6 & 25.5 & 23.9 & 28.2 & 28.6 \\
\hline \multicolumn{7}{|c|}{ Humid PLA } \\
\hline & Virgin & $1^{\text {st }}$ cycle & $2^{\text {nd }}$ cycle & $3^{\text {rd }}$ cycle & $4^{\text {th }}$ cycle & $5^{\text {th }}$ cycle \\
\hline$T_{g}\left({ }^{\circ} \mathrm{C}\right)$ & 60.55 & 61.14 & 60.74 & 60.59 & 60.49 & 60.20 \\
\hline $\mathbf{T}_{\mathrm{c}}\left({ }^{\circ} \mathrm{C}\right)$ & 129.45 & 117.06 & 113.50 & 112.64 & 112.30 & 112.20 \\
\hline$\Delta \mathbf{H}_{\mathrm{cc}}(\mathrm{J} / \mathrm{g})$ & 0.977 & 18.70 & 23.07 & 22.69 & 25.85 & 25.55 \\
\hline $\mathbf{T}_{\mathrm{m}}\left({ }^{\circ} \mathrm{C}\right)$ & 151.28 & 149.87 & 150.11 & 149.77 & 148.93 & 149.49 \\
\hline$\Delta \mathbf{H}_{\mathrm{m}}(\mathrm{J} / \mathrm{g})$ & 1.161 & 22.31 & 24.29 & 22.18 & 25.30 & 29.09 \\
\hline$X_{c}(\%)$ & 1.2 & 24.0 & 26.1 & 23.8 & 27.2 & 31.2 \\
\hline
\end{tabular}


no change on the temperature of glass transition $\left(\mathrm{T}_{\mathrm{g}}\right)$, which remains around $60^{\circ} \mathrm{C}$ for all samples, with a variation of less than $1^{\circ} \mathrm{C}$. Reduction on the glass transition temperature could be related to the presence of more chain ends, and the increase of free volume caused by them. Or related to the presence of fragments from chain scission which could act as plasticizers for the material. Either way, considering the extent of molecular weight reduction, the increase in free volume, or chain fragments, is not significant to a dramatic decrease of $\mathrm{T}_{\mathrm{g}}$ determined by $\mathrm{DSC}^{2}$.

The crystallization behavior also remains the same. All samples have significant exothermic peaks due to cold crystallization, whose magnitude, in most cases, equals to the values of the endothermic melting peaks, which indicates that, in these conditions of cooling, the samples are amorphous. Some samples may have presented a more relevant difference between cold crystallization enthalpy ( $\Delta \mathrm{Hcc}$ ) and melt enthalpy $\left(\Delta \mathrm{H}_{\mathrm{m}}\right)$, but this is considerably more related to the indistinct separation of the two peaks of interest, as observed by Zenkiewicz et al than to a tendency of increase crystallinity.

There is, however, a tendency to an increase of the values of both enthalpies, which could be related to an increase of the potential of crystallization of these materials. The increase of crystallinity could not be noticed on the final material due to the reduction of nucleating and growth rate caused by the presence of $4 \%$ of $\mathrm{D}$-isomer. The increase on the potential of crystallization is, though, explained by the molecular weight reduction, as smaller chains have higher mobility to be crystallized ${ }^{24}$. Moreover, this phenomenon occurred at lower temperatures compared to the virgin PLA, as can be seen by the cold crystallization temperature $\left(\mathrm{T}_{\mathrm{c}}\right)$, and there was a trend towards $T_{c}$ reduction along with extrusion cycles, probably due to reduced molecular weight of these formulations. On the other hand, melt temperature $\left(\mathrm{T}_{\mathrm{m}}\right)$ showed similar results for all samples.

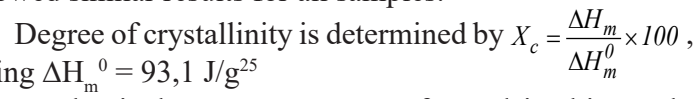

Mechanical tests were not performed in this work, nonetheless, comparing with the literature on multiple processing of $\mathrm{PLA}^{1,2,9,19}$, it is possible to infer that the mechanical properties could be diminished, with a tendency of decrease of tensile strength and impact strength. However, these results are often observed to molecular weight decreases higher than those obtained in this work, caused by more than five cycles of extrusion, or cycles of injection molding.

The multiple extrusion process leads to visually noticeable yellowing, which is an undesirable effect for several applications, such as packaging. Figure 5 illustrates this effect. The quantification of this color change was approached with CIELab coordinates and ASTM E313 yellowness index (YI). Those results are shown on Table 3.

As a general trend, color formation is associated with degradation, with an increase of the yellowness index proportional to the molecular weight decrease. There is a strong deviation to yellow, noticed by the higher values of ' $b$ ' coefficient, but there are also deviations to red, with values of ' $a$ ' becoming positive and a darkening of the samples with the decrease of ' $L$ '.

Yellowing is associated with the increase of chromophore groups, whose conjugation causes absorption on higher wavelengths. Considering the degradation mechanisms of PLA, cis-elimination produces chain scission with the formation of a terminal double bond, which in conjugation with the nearest carbonyl double bond would form a chromophore. On the classical papers of polylactide degradation via pyrolysis ${ }^{17,18}$, however without shear and oxidative atmosphere, this mechanism is considered secondary.

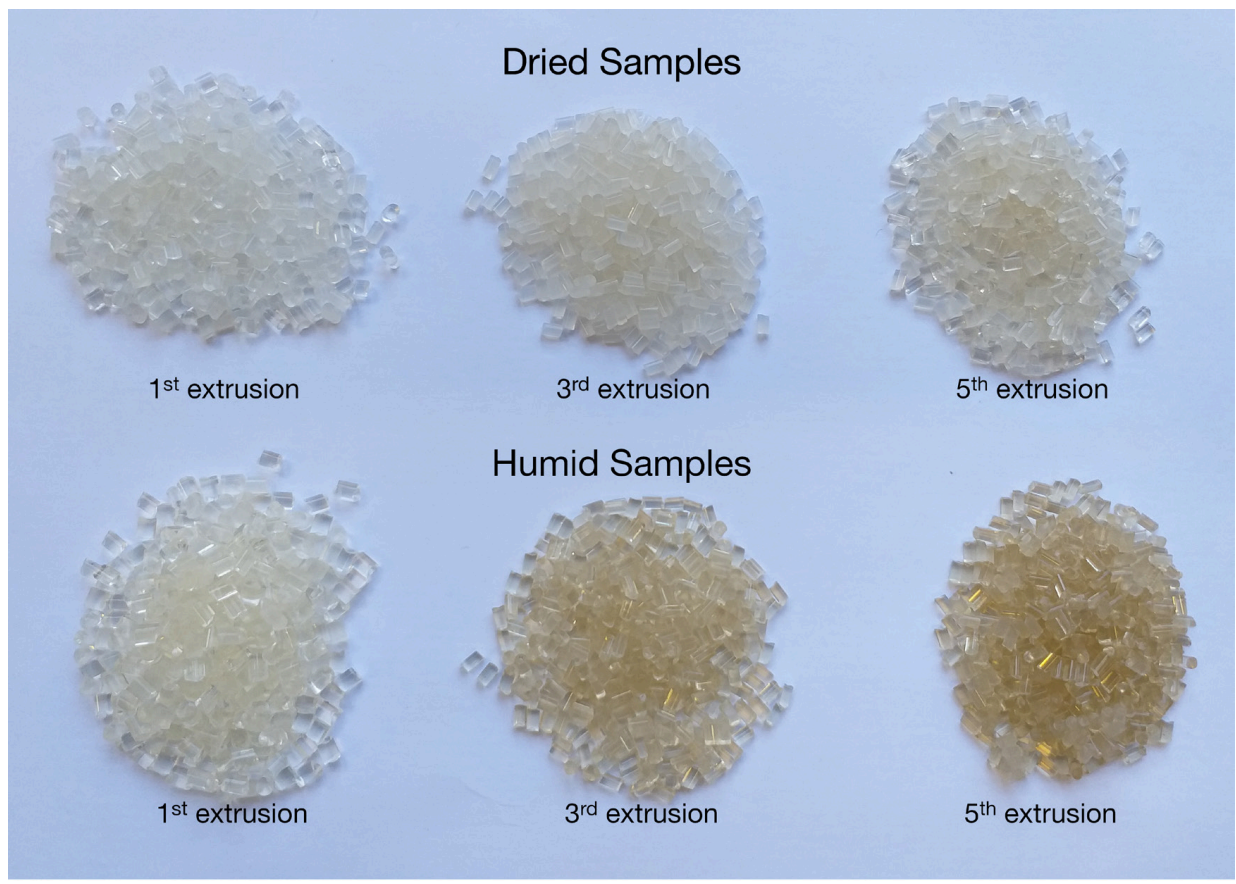

Figure 5. Extrudates from different extrusion cycles for visual illustration purposes 
Table 3: Colorimetric data from selected samples of the multiple extruded PLA

\begin{tabular}{|c|c|c|c|c|c|}
\hline \multicolumn{6}{|c|}{ Dried PLA } \\
\hline & $\mathbf{L}$ & $\mathbf{a}$ & b & $\Delta \mathbf{E}$ & Yellowness Index (YI) \\
\hline & (0) dark to light (100) & (-) green to red (+) & $\overline{(-) \text { blue to yellow }(+)}$ & (variation of color) & ASTM E313 \\
\hline Virgin & 84.43 & -0.14 & 3.37 & - & 6.94 \\
\hline $1^{\text {st }}$ cycle & 85.10 & -0.12 & 3.18 & 0.69 & 6.52 \\
\hline $3^{\text {rd }}$ cycle & 82.58 & -0.11 & 4.49 & 2.17 & 9.43 \\
\hline $5^{\text {th }}$ cycle & 83.30 & 0.03 & 4.93 & 1.94 & 10.38 \\
\hline \multicolumn{6}{|c|}{ Humid PLA } \\
\hline & $\mathbf{L}$ & $\mathbf{a}$ & b & $\Delta \mathbf{E}$ & $\begin{array}{c}\text { Yellowness Index } \\
\text { (YI) }\end{array}$ \\
\hline & (0) dark to light (100) & (-) green to red (+) & $\overline{(-) \text { blue to yellow }(+)}$ & (variation of color) & ASTM E313 \\
\hline Virgin & 84.43 & -0.14 & 3.37 & - & 6.94 \\
\hline $1^{\text {st }}$ cycle & 82.34 & -0.03 & 4.98 & 2.64 & 10.52 \\
\hline $3^{\text {rd }}$ cycle & 79.03 & 0.28 & 9.46 & 8.16 & 20.41 \\
\hline
\end{tabular}

On the other hand, hydrolysis mechanisms are not responsible for the formation of conjugated bonds. Therefore, it would be expected from the dried samples to have higher yellowness indexes than the humid ones, as former discussed on literature by Wang et al. ${ }^{26}$. Nonetheless, the findings of the present work point to the opposite. The humid samples presents more discoloration than the dried ones. Meanwhile, as the material used in this experiments is a commercial polymer, it would be expected to contain additives, such as hydrolysis stabilizers, in its formulation, which could be the responsible for the color formation, however this hypothesis is yet to be tested on further studies.

\section{Conclusions}

This study of multiple extrusions of PLA allowed to have an insight on the degradation of the material in conditions similar to reprocessing and recycling. Despite being a biodegradable material, it would be beneficial, in terms of cost reduction, to increase its life cycle time through mechanical recycling.

The mechanisms of degradation were addressed by analyzing the results of SEC, acidity and colorimetry. Hydrolysis, induced by the presence of moisture, is preponderant to a more drastic reduction of molecular weight, when compared to dried samples, which were assumed to suffer only thermal degradation. Polydispersity and acidity support the hypothesis of random mechanisms of chain cleavage instead of a chain-end preferential route. Discoloration would endorse the predominance of cis-elimination among thermal mechanisms, since it is the only capable of produce conjugated double bonds. However, stronger discoloration on humid samples, implied that the color developing may not be due, primarily, to reactions of scission from the main PLA chain, which is to be investigated.

Results suggest that PLA is a good candidate to mechanical recycling, as reduction of molecular weight is not drastic even after five cycles of extrusion, showing a maximum decrease of $30 \%$, when drying protocol is not applied, which is unconventional. Other properties, as thermal properties, remain practically unaltered along with cycles, yet, discoloration, as discussed above, may be a restraint for some of its applications.

\section{Acknowledgements}

This study was financed in part by the Coordenação de Aperfeiçoamento de Pessoal de Nível Superior - Brasil (CAPES) - Finance Code 001. The authors also are grateful for the support of the Postgraduate Program in Materials Science and Engineering (PPGCEM) and the fundings by Conselho Nacional de Desenvolvimento Científico e Tecnológico (CNPq) (Processo 134656/2016-4), and Fundação de Amparo à Pesquisa do Estado de São Paulo (FAPESP) (Processo 2011/21313-1)

\section{References}

1. Taubner V, Shishoo R. Influence of processing parameters on the degradation of poly(L-lactide) during extrusion. J Appl Polym Sci. 2001;79(12):2128-35.

2. Badia JD, Strömberg E, Karlsson S, Ribes-Greus A. Material valorisation of amorphous polylactide. Influence of thermomechanical degradation on the morphology, segmental dynamics, thermal and mechanical performance. Polym Degrad Stab. 2012;97(4):670-8. http://dx.doi.org/10.1016/j. polymdegradstab.2011.12.019.

3. Hopmann C, Schippers S, Höfs C. Influence of recycling of poly(lactic acid) on packaging relevant properties. J Appl Polym Sci. 2015;132(9):1-6.

4. Belgacem MN, Gandini A. [Internet]. Monomers, Polymers and Composites from renewable resources. Amsterdam: Elsevier; 2008 [cited 2020 Sep 19]. Available from: http://www.sciencedirect. com/science/article/pii/B9780080453163000132

5. Lamberti FM, Román-Ramírez LA, Wood J. Recycling of bioplastics: routes and benefits. J Polym Environ. 2020;28(10):2551-71. http://dx.doi.org/10.1007/s10924-020-01795-8.

6. Badia JD, Ribes-Greus A. Mechanical recycling of polylactide, upgrading trends and combination of valorization techniques. Eur Polym J. 2016;84:22-39. http://dx.doi.org/10.1016/j. eurpolymj.2016.09.005.

7. Soroudi A, Jakubowicz I. Recycling of bioplastics, their blends and biocomposites: A review. Eur Polym J. 2013;49(10):283958. http://dx.doi.org/10.1016/j.eurpolymj.2013.07.025.

8. Cosate de Andrade MF, Souza PMS, Cavalett O, Morales AR. Life cycle assessment of Poly(Lactic Acid) (PLA): Comparison between chemical recycling, mechanical recycling and composting. J Polym Environ. 2016;24(4):372-84.

9. Zenkiewicz M, Richert J, Rytlewski P, Moraczewski K, Stepczyńska M, Karasiewicz T. Characterisation of multiextruded poly(lactic acid). Polym Test. 2009;28(4):412-8. 
10. Carrasco F, Pagès P, Gámez-Pérez J, Santana OO, Maspoch ML. Processing of poly(lactic acid): Characterization of chemical structure, thermal stability and mechanical properties. Polym Degrad Stab [Internet]. 2010;95(2):116-25. [cited 2020 Sep 19]. Available from: http://linkinghub.elsevier.com/retrieve/ pii/S014139100900408X.

11. Beltrán FR, Lorenzo V, Acosta J, de la Orden MU, Martínez Urreaga J. Effect of simulated mechanical recycling processes on the structure and properties of poly(lactic acid). J Environ Manage. 2018;216:25-31.

12. Zhao P, Rao C, Gu F, Sharmin N, Fu J. Close-looped recycling of polylactic acid used in 3D printing: an experimental investigation and life cycle assessment. J Clean Prod. 2018;197:1046-55.

13. Cosate de Andrade MF, Fonseca G, Morales AR, Mei LHI. Mechanical recycling simulation of polylactide using a chain extender. Adv Polym Technol. 2018;37(6):2053-60.

14. Beltrán FR, Infante C, de la Orden MU, Martínez Urreaga J. Mechanical recycling of poly(lactic acid): evaluation of a chain extender and a peroxide as additives for upgrading the recycled plastic. J Clean Prod. 2019;219:46-56.

15. Rigolin TR, Costa LC, Chinelatto MA, Muñoz PAR, Bettini SHP. Chemical modification of poly(lactic acid) and its use as matrix in poly(lactic acid) poly(butylene adipate-co-terephthalate) blends. Polym Test. 2017;63:542-9. http://dx.doi.org/10.1016/j. polymertesting.2017.09.010.

16. Yu H, Huang N, Wang C, Tang Z. Modeling of poly(L-lactide) thermal degradation: theoretical prediction of molecular weight and polydispersity index. JAppl Polym Sci. 2003;88(11):2557-62. http:// dx.doi.org/10.1002/app.12093\%5Cnhttp://www3.interscience.wiley. com/cgi-bin/fulltext?ID=104085968\&PLACEBO=IE.pdf\&mode=pdf.

17. McNeill IC, Leiper HA. Degradation studies of some polyesters and polycarbonates - 1. Polactide: general features of the degradation under programmed heating conditions. Polym Degrad Stabil. 1985;11:267-85.

18. Kopinke F-D, Remmler M, Mackenzie K, Möder M, Wachsen O. Thermal decomposition of biodegradable polyesters-II. Poly(lactic acid). Polym Degrad Stab [Internet]. 1996;53(3):329-
42. [cited 2020 Sep 19]. Available from: http://linkinghub. elsevier.com/retrieve/pii/0141391096001024

19. Pillin I, Montrelay N, Bourmaud A, Grohens Y. Effect of thermo-mechanical cycles on the physico-chemical properties of poly(lactic acid). Polym Degrad Stab [Internet]. 2008;93(2):321-8. [cited 2020 Sep 19]. Available from: http://linkinghub.elsevier. com/retrieve/pii/S0141391007003758.

20. Taubner V, Shishoo R. Influence of Processing Parameters on the Degradation of Poly (L -lactide) During Extrusion. J Appl Polym Sci. 2001;79:2128-35.

21. Lucas N, Bienaime C, Belloy C, Queneudec M, Silvestre F, Nava-Saucedo J-E. Polymer biodegradation: mechanisms and estimation techniques - A review. Chemosphere. 2008;73(4):42942.

22. de Jong S, Arias E, Rijkers DT, van Nostrum C, Kettenes-van den Bosch J, Hennink W. New insights into the hydrolytic degradation of poly(lactic acid): participation of the alcohol terminus. Polymer (Guildf). 2001;42(7):2795-802.

23. Amorin NSQS, Rosa G, Alves JF, Gonçalves SPC, Franchetti SMM, Fechine GJM. Study of thermodegradation and thermostabilization of poly(lactide acid) using subsequent extrusion cycles. J Appl Polym Sci. 2014;131(6):1-8. http:// dx.doi.org/10.1002/app.40023.

24. Androsch R, Schick C, Di Lorenzo ML. Kinetics of Nucleation and Growth of Crystals of Poly(l-lactic acid). In: Di Lorenzo ML, Androsch R. Synthesis, Structure and Properties of Poly (lactic acid) [Internet]. Springer; 2017. p. 235-72. [cited 2020 Sep 19]. Available from: http://link.springer. com/10.1007/12_2016_13

25. Fischer EW, Sterzel HJ, Wegner G. Investigation of the structure of solution grown crystals of lactide copolymers by means of chemical reactions. Kolloid-Zeitschrift Zeitschrift für Polym. 1973;251(11):980-90.

26. Wang Y, Steinhoff B, Brinkmann C, Alig I. In-line monitoring of the thermal degradation of poly(l-lactic acid) during melt extrusion by UV-vis spectroscopy. Polymer (Guildf). 2008;49(5):125765. http://dx.doi.org/10.1016/j.polymer.2008.01.010. 